\title{
Binding versus Conventional Pancreaticojejunostomy in Preventing Postoperative Pancreatic Fistula: A Systematic Review and Meta-Analysis
}

\author{
Xianbin Zhang ${ }^{a, b} \quad$ Xin Dong $^{b} \quad$ Peng Liu $^{b} \quad$ Yumei Yan ${ }^{c}$ \\ Yushan Wei $^{d}$ Dietmar Zechner ${ }^{a}$ Peng Gong ${ }^{b}$ Brigitte Vollmar ${ }^{a}$ \\ ${ }^{a}$ Institute for Experimental Surgery, Rostock University Medical Center, Rostock, Germany; ${ }^{b}$ Department of

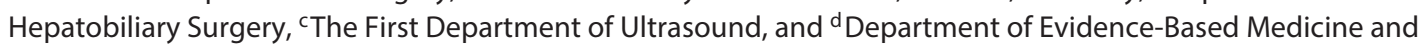 \\ Statistics, The First Affiliated Hospital of Dalian Medical University, Dalian, China
}

\section{Key Words}

Binding pancreaticojejunostomy · Pancreaticojejunostomy · Pancreaticoduodenectomy · Postoperative pancreatic fistula

\begin{abstract}
Background: The aim of this study was to compare the safety and efficacy of a new technology, binding pancreaticojejunostomy (BPJ), with conventional pancreaticojejunostomy (CPJ) after pancreaticoduodenectomy in preventing postoperative pancreatic fistula (POPF). Methods: Randomized controlled trials and observational studies were retrieved from literature searches. Pooled OR with $95 \% \mathrm{Cl}$ for dichotomous variables and weighted mean difference with $95 \% \mathrm{Cl}$ for continuous variables were calculated. Fixed-effect and random-effect models as well as subgroup analysis were used for sensitivity analysis. Results: No statistically significant differences were found in the incidence of POPF, delayed gastric emptying, postpancreatectomy hemorrhage, reoperation, morbidity, mortality, operation time, intraoperative blood loss, blood transfusion, and hospital stay between 2 groups. However, the total costs of hospitalization and ordinary stay were higher in BPJ group (€10,513 $\pm € 6,536$
\end{abstract}

\section{KARGER}

E-Mail karger@karger.com

www.karger.com/dsu vs. $€ 8,238 \pm € 4,687, p=0.002 ; € 7,946 \pm € 5,023$ vs. $€ 5,700 \pm$ $€ 2,902, p=0.015$, respectively). Conclusions: Our study showed BPJ was as safe as CPJ. However, no significant superiority was found in BPJ group regarding the incidence of POPF. The total costs of hospital stay were higher for patients undergoing BPJ. Surgeons can prefer to perform the digestive tract reconstruction of their choice.

(c) 2017 S. Karger AG, Basel

\section{Introduction}

Pancreaticoduodenectomy (PD) is a common surgical procedure to treat carcinoma of the pancreas head or periampullary region. Recent advances in surgical techniques and perioperative treatments have reduced the perioperative mortality below $5 \%$ in high volume centers [1-4]. However, PD is associated with considerable morbidity in $40-58.5 \%$ of patients manifesting postoperative pancreatic fistula (POPF), delayed gastric emptying (DGE), postpancreatectomy hemorrhage (PPH), and postoperative pulmonary complications $[2,5,6]$.

POPF is a common and most important complication following PD. It not only prolongs hospital stay and in-

Peng Gong

Department of Hepatobiliary Surgery

The First Affiliated Hospital of Dalian Medical University

Zhongshan Road No. 222, Dalian 116011 (China)

E-Mail gongpengdalian@163.com 
creases healthcare costs, but also plays a central role in the development of life-threatening events such as intra-abdominal abscess and PPH [7-10]. Several surgical techniques and perioperative care have been studied in order to prevent or decrease the incidence of POPF after PD, including digestive tract reconstruction with pancreaticogastrostomy [11], duct to mucosa or invagination pancreaticojejunostomy (PJ) [12], prophylactic somatostatin or somatostatin analogues [13], fibrin glue sealants [14], and pancreatic duct stents [15]. However, even in highvolume centers, the incidence of POPF is still in the range of 9.9-28.5\% [16-18]. An ideal pancreatic reconstruction technique or perioperative treatment, which prevents POPF, is still unavailable.

Since 2002, Peng et al. [19-21] reported a series of studies to describe a new technique, binding PJ (BPJ), associated with pancreatic fistula incidence of $0 \%$. In 2007 , Peng et al. [22] presented one randomized clinical trial (RCT) and concluded that BPJ prevented POPF, thus reducing complications and hospital stay. However, a casematched study from France showed that BPJ failed to prevent POPF and appeared to increase $\mathrm{PPH}$ [23]. Thus, the safety and efficacy of BPJ for the prevention of POPF after $\mathrm{PD}$ is still unclear.

To date, no systematic review or meta-analysis has been conducted to resolve the controversy of BPJ. Thus, the aim of the present study was to investigate the safety and efficacy of BPJ in terms of POPF.

\section{Materials and Methods}

The meta-analysis was performed according to the PRISMA statement [24] and the Cochrane Handbook for Systematic Reviews of Interventions [25].

\section{Ethical Statement}

The original data of this meta-analysis were based on previous published studies, thus no patients' consent and ethical approval are required.

Data Sources and Searches

Two authors (X.D. and P.L.) independently searched MEDLINE (Ovid SP, 1946-present), PubMed (1948-present), Embase (1947present), Science Citation Index Expanded (1981-present), Chinese Biomedical Literature Database (1975-present), and China National Knowledge Infrastructure (1979-present) using the following search strategy (PubMed): (peng [All Fields] OR binding [All Fields]) AND (PJ [MeSH Terms] OR PJ [All Fields] OR pancreaticojejunostomies [All Fields] OR pancreatojejunostomy [All Fields] OR pancreatojejunostomies [All Fields] OR pancreaticojejunal anastomosis [All Fields]). In addition, we also searched ClinicalTrials.gov, Cochrane Central Register of Controlled Trials in The Cochrane Library, and the reference lists of the identified reviews.
Study Selection

Two authors (X.Z. and X.D.) independently performed the study selection by screening the titles and abstracts according to the following inclusion and exclusion criteria. Any disagreements with respect to study selection, quality assessment, and data extraction were resolved by consensus.

Inclusion criteria: (1) human clinical studies and pre-review publications; (2) interventions of BPJ compared with conventional PJ (CPJ); (3) if there were more than 1 studies published by the same group, only the most recent one was included.

Exclusion criteria: (1) animal studies; (2) reviews, case reports, conference abstracts, letters to the editor, cohort studies only focusing on BPJ without control group; (3) studies without definition of POPF; and (4) studies without description of any of the following known risk factors of POPF after PD: body mass index (BMI) [26], pancreas texture [27], and pancreatic duct diameter [28].

\section{Quality Assessment}

The quality of included studies was assessed by 2 authors (X.Z. and X.D.). The Cochrane Risk of Bias Tool was used for quality assessment of RCT considering of random sequence generation, allocation concealment, blinding of participants and personnel, blinding of outcome assessment, incomplete outcome data, and selective reporting [25]. In addition, the Newcastle-Ottawa Quality Assessment Scale was used to assess the quality of non-randomized studies [29], and it was modified to suit our study (online suppl. Table 1, see www.karger.com/doi/10.1159/000453552). This modified Newcastle-Ottawa Quality Assessment Scale included 9 items to assess selection bias, comparability, and study outcomes. Stars were awarded for each high quality item and the highest quality studies were awarded up to 9 stars. A study with 6 or more than 6 stars was considered to be a high quality study, which was chosen as well in other meta-analysis [30].

\section{Outcomes of Interest}

The primary outcome of interest was the incidence of POPF in patients undergoing BPJ or CPJ. Secondary outcomes were DGE, $\mathrm{PPH}$, reoperation, morbidity, mortality, operation time, intraoperative blood loss and transfusion, hospital stay, and cost.

\section{Data Extraction}

Two authors (X.D. and Y.Y.) independently extracted the following data from each study: demographic characteristics (first author, location, study period, study design, sample size, operation performed, type of resection, age, gender, BMI, pancreatic texture, and pancreatic duct diameter) and outcomes of interest described above.

\section{Statistical Analysis}

OR and 95\% CIs were used to describe the results of meta-analysis for dichotomous variables and weighted mean difference (WMD) for continuous variables. The chi-square test was used to assess the heterogeneity with significance $p \leq 0.10$. $I^{2}$ statistic was used to quantitatively describe variability due to heterogeneity rather than chance. An $I^{2}$ value less than 25\% suggested low heterogeneity, which might not be important. An $I^{2}$ value between 25 and $50 \%$ indicated moderate heterogeneity, 50-75\% indicated substantial heterogeneity, and $75-100 \%$ represented considerable heterogeneity [25]. Fixed-effect and random-effect models as well 
Fig. 1. Flow diagram for the systematic literature search and selection strategy.

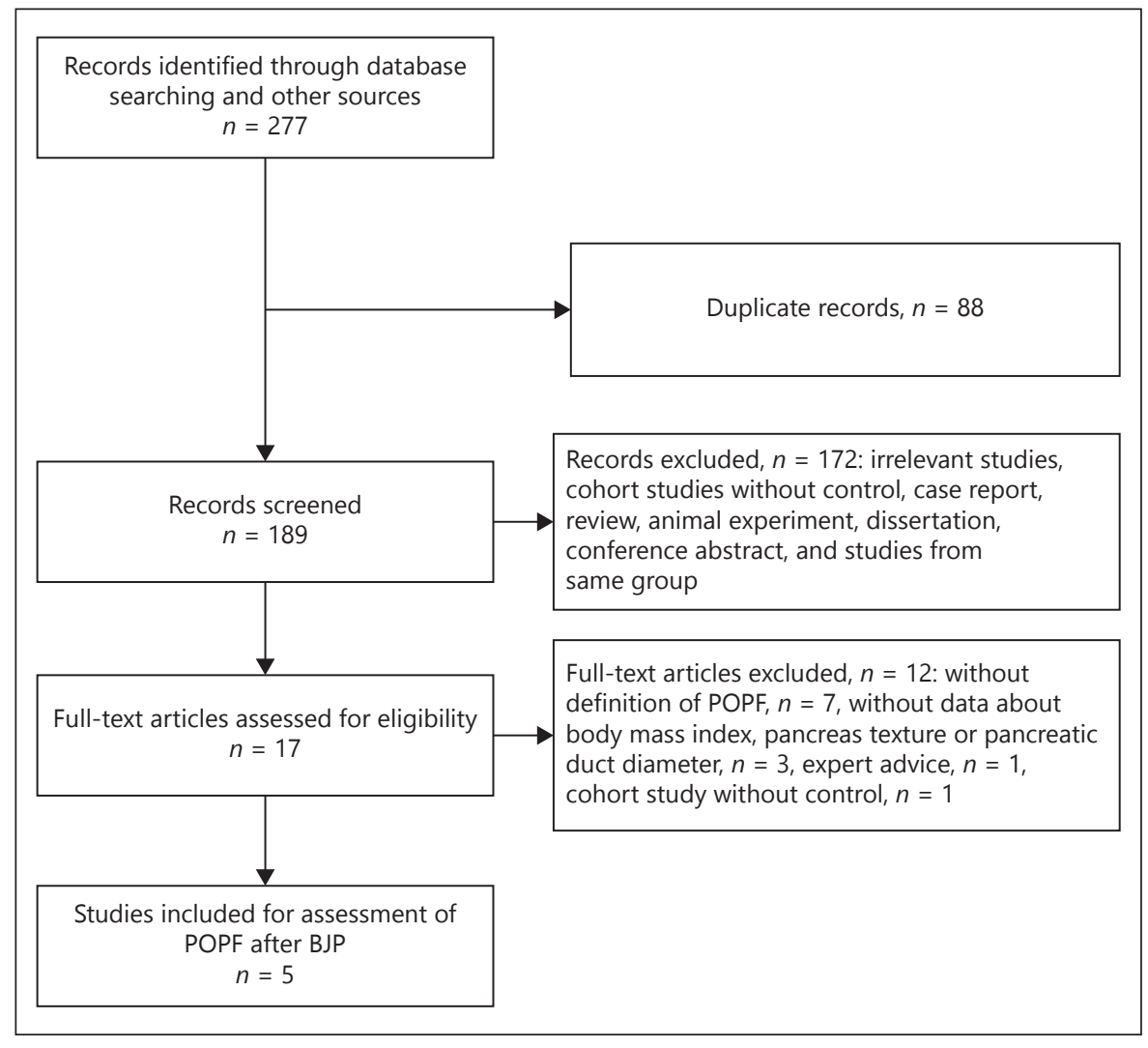

as subgroup analysis based on definition of POPF and International Study Group on Pancreatic Fistula Definition (ISGPF) grades (A, B, and C) were used for sensitivity analysis [31]. All statistical analyses were performed using the STATA version 12.0 (College Station, TX, USA) and Review Manager 5.3 for Windows (Wintertree Software, Inc., Nepean, ON, Canada).

\section{Results}

\section{Study Selection}

A total 277 records were retrieved, and after deleting 88 duplicate records, 172 records were excluded according to the exclusion criteria by screening the title and abstract. The remaining 17 full-text articles were assessed. Of these, 7 articles without definition of POPF; 3 articles without data related to BMI, pancreatic texture, and pancreatic duct diameter; 1 article about expert advice; and 1 article without control group were excluded (Fig. 1).

\section{Characteristics and Qualities of Included Studies}

Finally, 5 studies including 1 RCT [22] and 4 observational studies (OBSs) [23, 32-34] were included for assessment of safety and efficacy of BPJ in preventing
POPF of patients after PD. The patient demographics and quality of each study are summarized in Table 1, 3, and 4 , and the main study outcomes are defined in Table 2 .

\section{Primary Outcome}

Postoperative Pancreatic Fistula

Five studies [22, 23, 32-34] involving 479 patients, 242 in the BPJ group and 237 in the CPJ group, were pooled to compare the incidence of POPF after PD. No significant differences existed between the 2 groups (OR 0.71 ; 95\% CI $0.28-1.76$ ). Moderate heterogeneity was observed among all studies $\left(I^{2}=35.2 \%, p=0.187\right.$; Fig. 2).

\section{Second Outcomes \\ Delayed Gastric Emptying}

Four studies [22, 23, 32, 34] involving 358 patients, including 173 in the BPJ group and 185 in the CPJ group, were pooled to compare the incidence of DGE in patients undergoing PD. No significant difference existed between the 2 groups (OR 1.24; 95\% CI 0.48-3.23). Low heterogeneity was observed among all studies $\left(I^{2}=0.0 \%\right.$, $p=0.886$; Fig. 3a). 


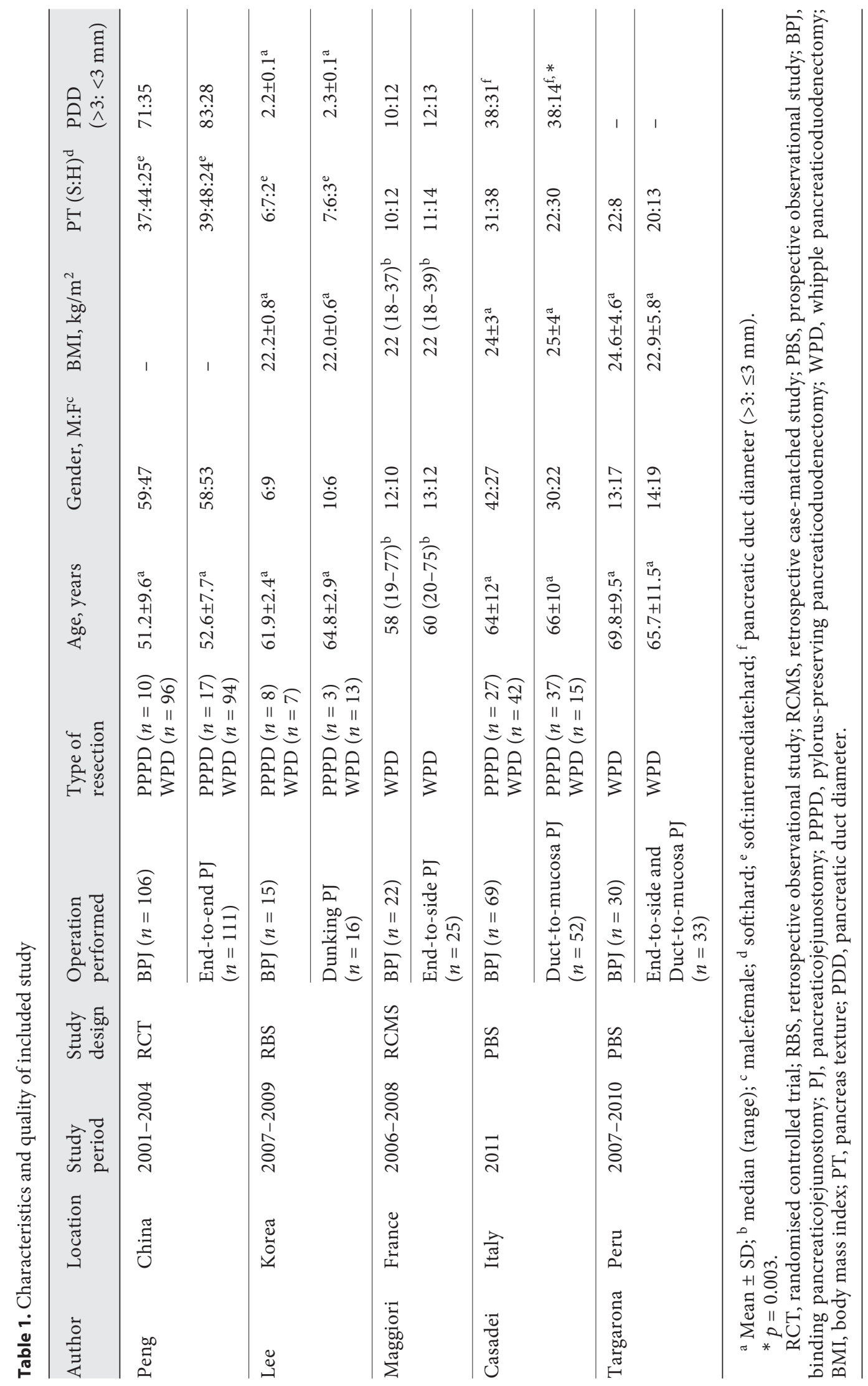




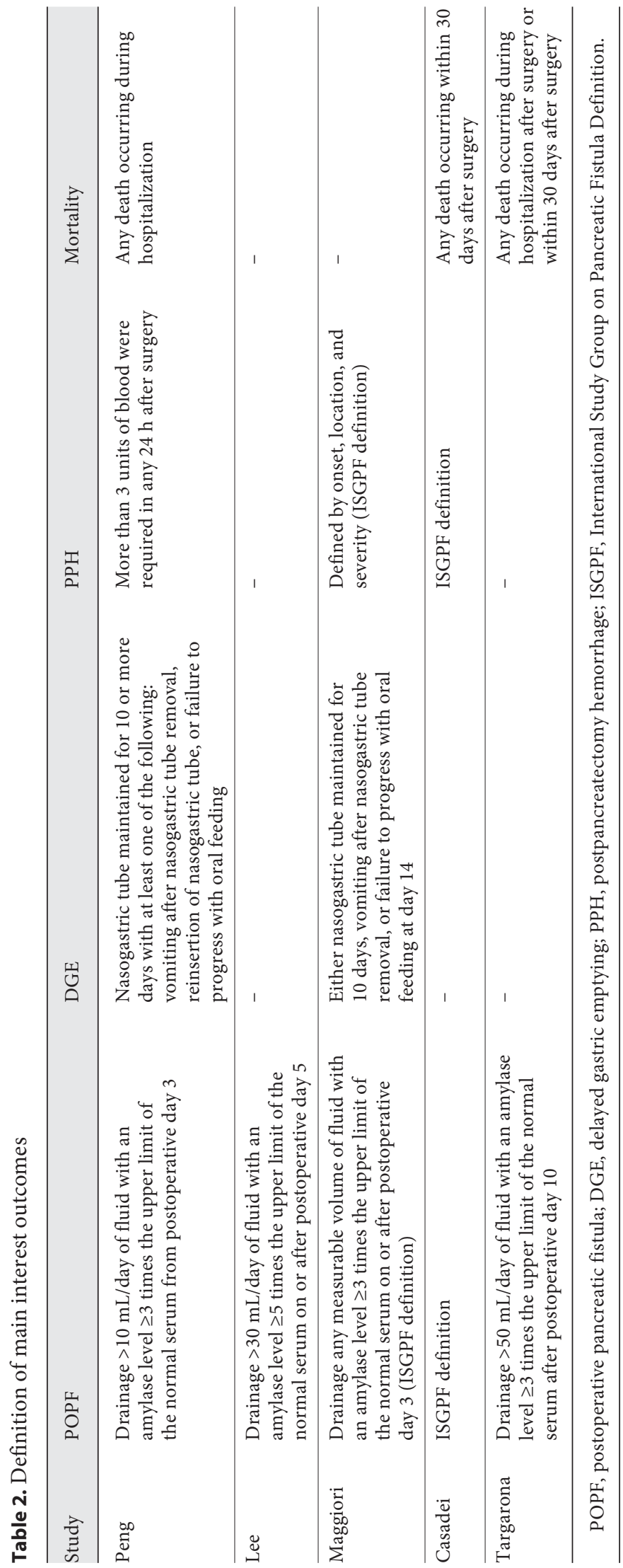

Binding Pancreaticojejunostomy
Postpancreatectomy Hemorrhage

Four studies $[22,23,33,34]$ involving 448 patients, including 227 in the BPJ group and 221 in the CPJ group, were pooled to compare the incidence of $\mathrm{PPH}$ in patients after PD. There was no significant difference between the 2 groups (OR 1.20; 95\% CI 0.34-4.27). Substantial heterogeneity was found among all the studies $\left(I^{2}=55.2 \%, p=\right.$ 0.082; Fig. 3b).

\section{Reoperation}

Four studies [22, 23, 33, 34] involving 448 patients, including 227 in the BPJ group and 221 in the CPJ group, were pooled to compare the incidence of reoperation in patients after PD. No significant differences occurred between the 2 groups (OR 1.07; 95\% CI 0.45-2.56). Low heterogeneity wasfound among all the studies $\left(I^{2}=0.0 \%, p=0.411\right.$; Fig. 4a).

\section{Morbidity}

Five studies [22, 23, 32-34] involving 479 patients, including 242 in the BPJ group and 237 in the CPJ group, were pooled to compare the incidence of morbidity in patients after PD. There was no significant difference between the 2 groups (OR $0.74 ; 95 \%$ CI $0.49-1.14$ ) and there was low heterogeneity among all the studies $\left(I^{2}=11.6 \%\right.$, $p=0.339$; Fig. 4b).

\section{Mortality}

Four studies [22, 23, 33, 34] involving 448 patients, including 227 in the BPJ group and 221 in the CPJ group, were pooled to compare the incidence of mortality in patients after PD. No significant differences were found between the 2 groups (OR 0.64; 95\% CI $0.23-1.83$ ) and the heterogeneity among all the studies was low $\left(I^{2}=\right.$ $0.0 \%, p=0.469$; Fig. $5 \mathrm{a}$ ).

\section{Operation Time}

Three studies [22, 32, 34] involving 311 patients including 151 in the BPJ group and 160 in the CPJ group were pooled to compare the operation time in patients undergoing BPJ or CPJ. There was no significant differences between the 2 groups (WMD $=0.28 ; 95 \% \mathrm{CI}-0.97$ to 1.53 ) and considerable heterogeneity existed among all the studies $\left(I^{2}=98.3 \%, p=0.000\right.$; Fig. $\left.5 b\right)$.

\section{Intraoperative Blood Loss and Transfusion}

Three studies $[22,32,34]$ involving 311 patients, including 151 in the BPJ group and 160 in the CPJ group, were pooled to compare intraoperative blood loss and transfusion in patients undergoing BPJ or CPJ. There was no significant difference between the 2 groups $(\mathrm{WMD}=$ 


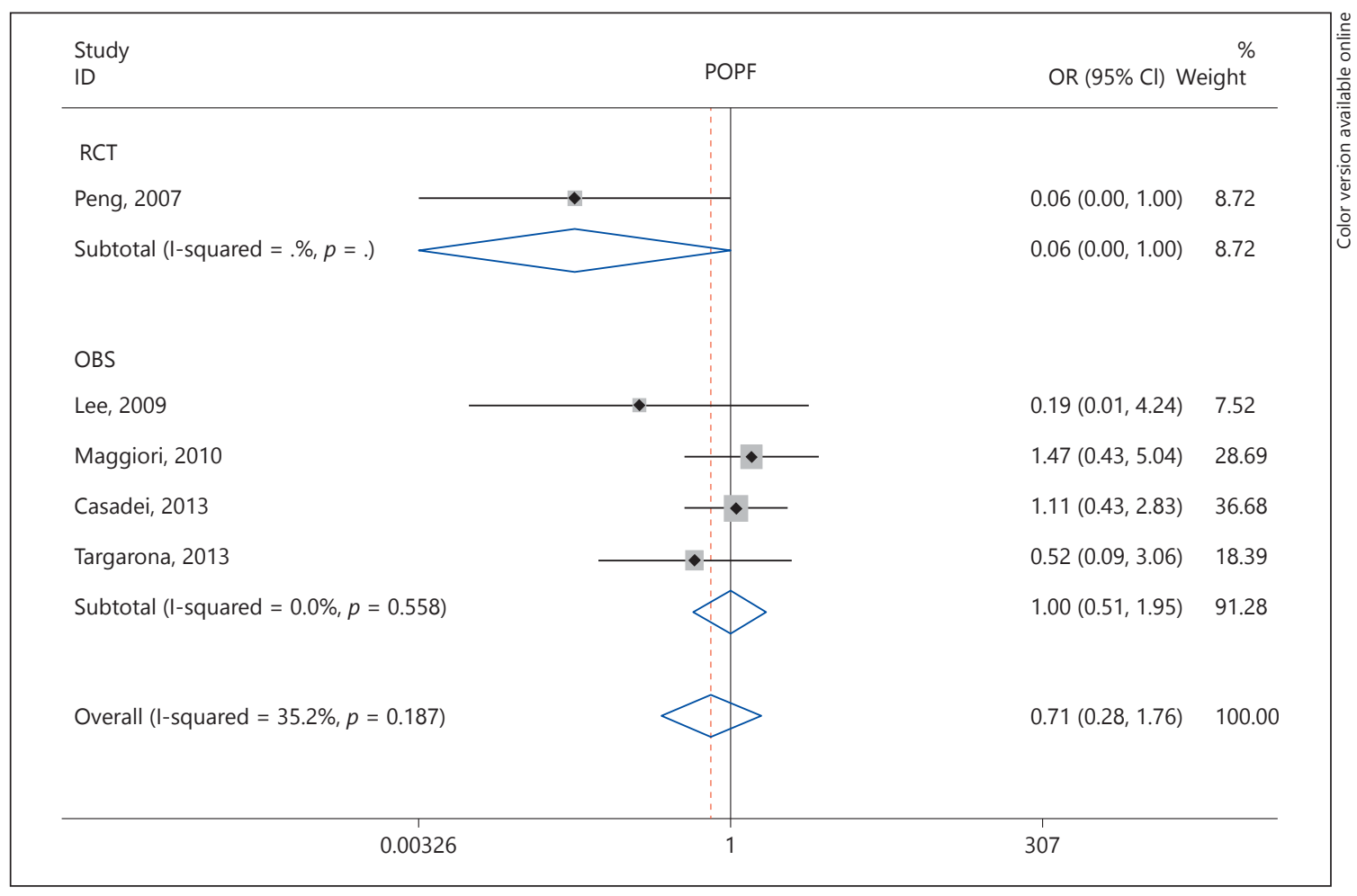

Fig. 2. Forest plot with RCT and OBSs showing OR of POPF for patients underwent BPJ and CPJ after pancreaticoduodenectomy (DerSimonian-Laird random-effect model). RCT, randomized controlled trial; OBS, observational study. Weights are from random effects analysis.

$-16.40 ; 95 \% \mathrm{CI}-124.96$ to 92.16 ; WMD $=-0.10 ; 95 \% \mathrm{CI}$ -0.56 to 0.36 , respectively). Substantial and considerable heterogeneity existed among all the studies $\left(I^{2}=\right.$ $62.9 \%, p=0.067 ; I^{2}=79.5 \%, p=0.008$, respectively; Fig. 6 ).

\section{Hospital Stay}

Four studies [22, 32-34] involving 432 patients, including 220 in the BPJ group and 212 in the CPJ group, were pooled to compare the patients' hospital stay. There was no significant difference between the 2 groups (WMD = $-0.18 ; 95 \% \mathrm{CI}-4.80$ to 4.44$)$. Considerable heterogeneity existed among all the studies $\left(I^{2}=88.9 \%, p<0.000\right)$. Three studies [33-35] were pooled to compare patients' stay in the intensive care unit (ICU) following PD. No significant difference existed between the 2 groups $(\mathrm{WMD}=0.24$; $95 \% \mathrm{CI}-0.57$ to 1.05$)$ and the heterogeneity among all the studies was substantial $\left(I^{2}=52.3 \%, p=0.123\right.$; Fig. 7$)$.

\section{Cost}

Only one study [33] mentioned cost of hospital stay. The total costs of hospital stay and ordinary stay in the BPJ group were higher than those in the control group
$(€ 10,513 \pm € 6,536$ vs. $€ 8,238 \pm € 4,687 ; p=0.002 ; € 7,946 \pm$ $€ 5,023$ vs. $€ 5,700 \pm € 2,902 ; p=0.015$; respectively). However, there were no significant differences in the cost of ICU stay $(€ 2,538 \pm € 3,292$ vs. $€ 2,566 \pm € 4885 ; p=0.156)$.

\section{Sensitivity Analysis}

No significant differences were found between the 2 groups in fixed-effect and random-effect models (data not shown). Subgroup analysis of all studies based on definition and grades of POPF showed no significant difference between the BPJ and CPJ groups (Fig. 8).

\section{Discussion}

The present meta-analysis compared the outcomes of a new PJ technique with the conventional CPJ to assess the safety and efficacy of BPJ in decreasing the incidence of POPF after PD. No major differences in POPF and other secondary outcomes (DGE, PPH, reoperation, morbidity, mortality, operation time, blood loss and transfusion, and hospital stay) were found between BPJ and CPJ 


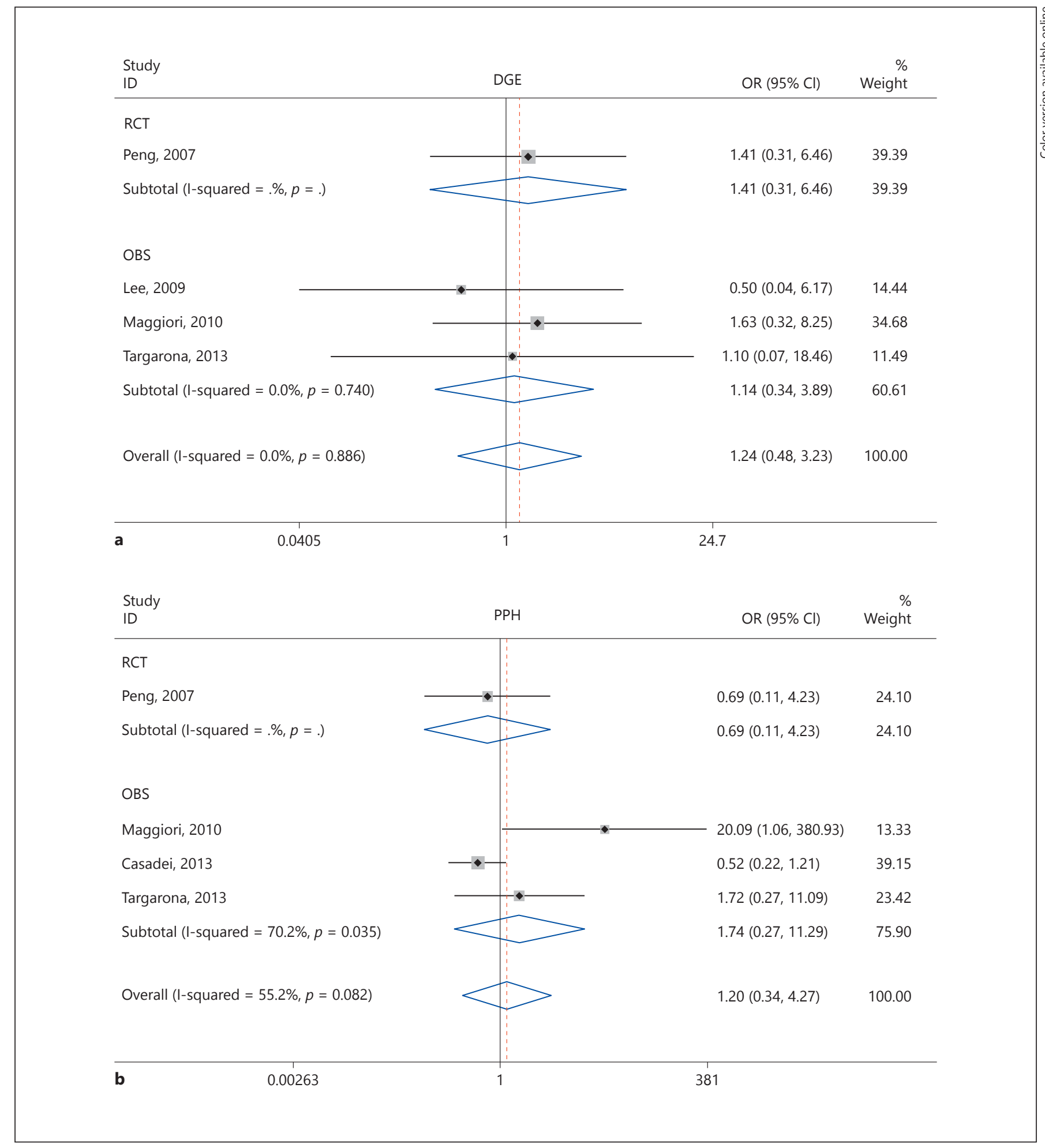

Fig. 3. Forest plot with RCT and OBSs showing OR of DGE (a) and PPH (b) for patients underwent BPJ and CPJ after pancreaticoduodenectomy (DerSimonian-Laird random-effect model). RCT, randomized controlled trial; OBS, observational study. Weights are from random effects analysis. 


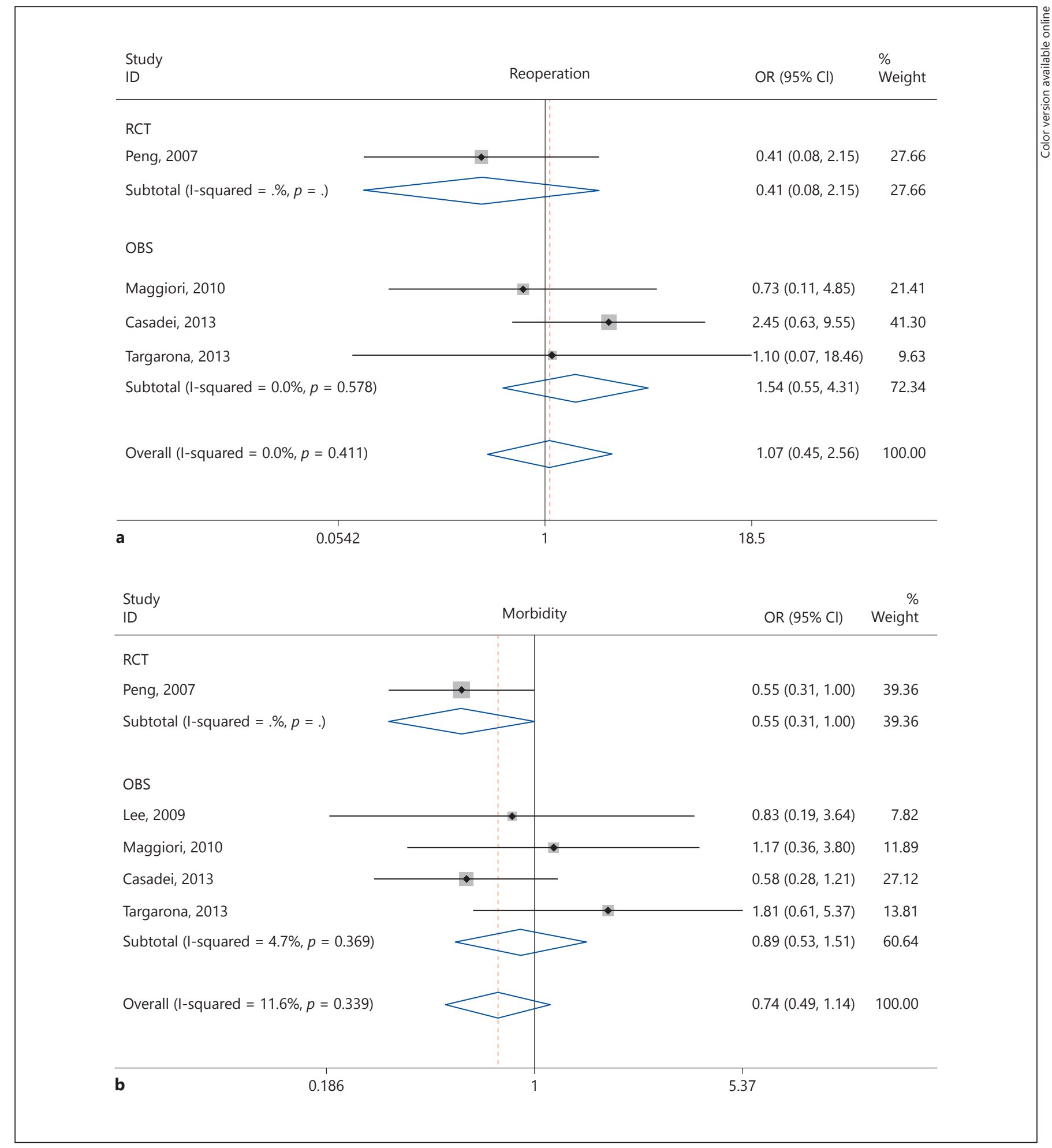

Fig. 4. Forest plot with RCT and OBSs showing OR of reoperation (a) and morbidity (b) for patients underwent BPJ and CPJ after pancreaticoduodenectomy (DerSimonian-Laird random-effect model). RCT, randomized controlled trial; OBS, observational study. Weights are from random effects analysis. 


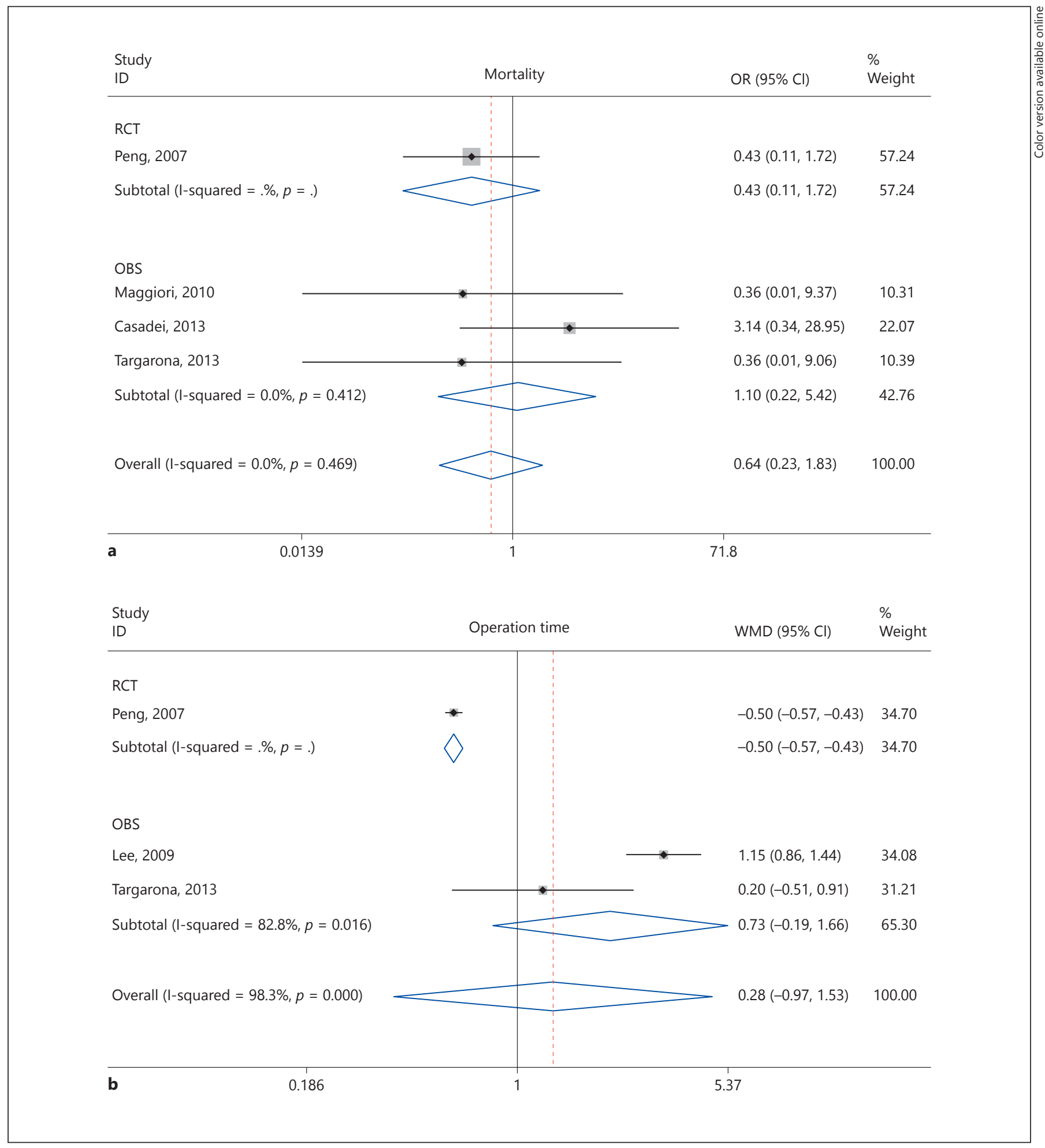

Fig. 5. Forest plot with RCT and OBSs showing OR of mortality (a) and WMD of operation time (b) for patients underwent BPJ and CPJ after pancreaticoduodenectomy (DerSimonian-Laird random-effect model). RCT, randomized controlled trial; OBS, observational study; WMD, weighted mean difference. Weights are from random effects analysis. 


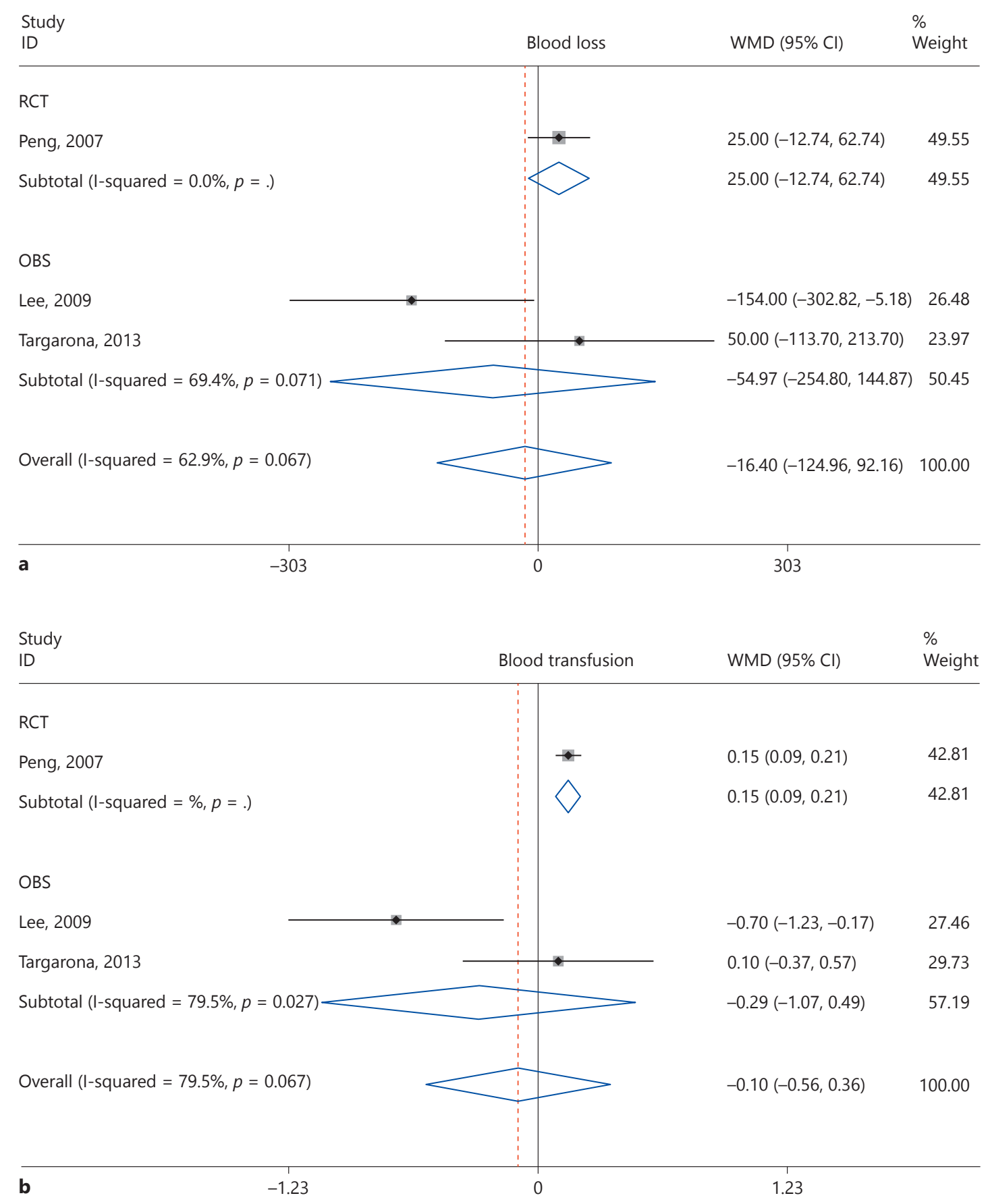

Fig. 6. Forest plot with RCT and OBSs showing WMD of intraoperative blood loss (a) and blood transfusion (b) for patients underwent BPJ and CPJ after pancreaticoduodenectomy (DerSimonian-Laird random-effect model). RCT, randomized controlled trial; OBS, observational study; WMD, weighted mean difference. Weights are from random effects analysis. 


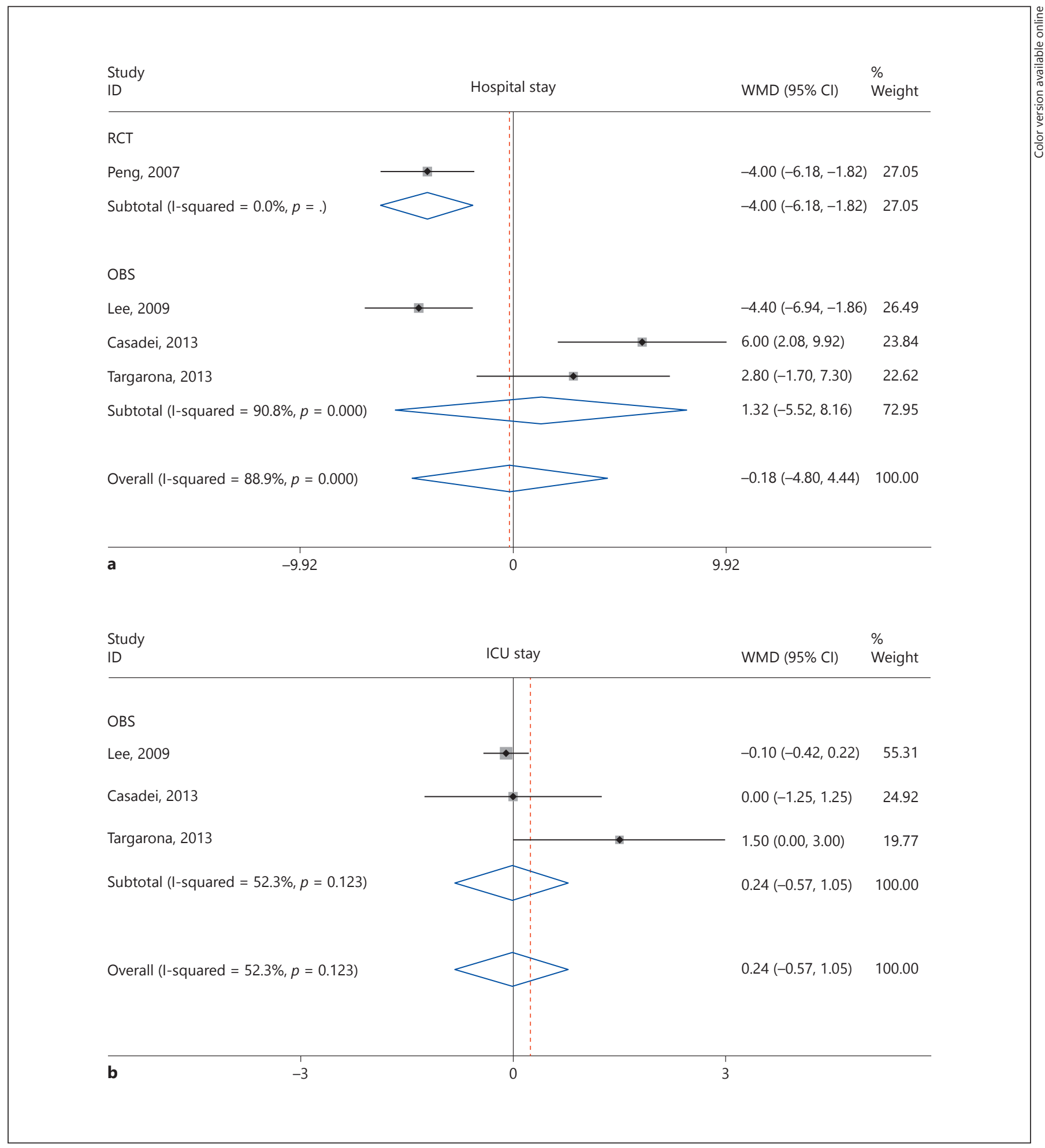

Fig. 7. Forest plot with RCT and OBSs showing WMD of hospital stay (a) and ICU stay (b) for patients underwent BPJ and CPJ after pancreaticoduodenectomy (DerSimonian-Laird random-effect model). RCT, randomized controlled trial; OBS, observational study; WMD, weighted mean difference. Weights are from random effects analysis. 


\begin{tabular}{|c|}
\hline $\begin{array}{l}\text { Study } \\
\text { ID }\end{array}$ \\
\hline Other definition \\
\hline Peng, 2007 \\
\hline Lee, 2009 \\
\hline ISGPF Definition \\
\hline Maggiori, 2010 \\
\hline Casadei, 2013 \\
\hline Subtotal $(I-$ squared $=0.0 \%, p=0.722)$ \\
\hline Overall (I-squared $=35.2 \%, p=0.187$ ) \\
\hline 0.00326 \\
\hline $\begin{array}{l}\text { Study } \\
\text { ID }\end{array}$ \\
\hline Grade A \\
\hline Maggiori, 2010 \\
\hline Casadei, 2013 \\
\hline Subtotal $(I-$ squared $=0.0 \%, p=0.356)$ \\
\hline Grade B \\
\hline Maggiori, 2010 \\
\hline Casadei, 2013 \\
\hline Subtotal $(I-$ squared $=0.0 \%, p=0.635)$ \\
\hline Grade C \\
\hline Maggiori, 2010 \\
\hline Casadei, 2013 \\
\hline Subtotal $(I-$ squared $=0.7 \%, p=0.316)$ \\
\hline Overall, I-squared $=0.0 \%, p=0.733$ \\
\hline 0.0073 \\
\hline
\end{tabular}

Fig. 8. Subgroup analysis based on definition (a) and grades of POPF (b) for patients underwent BPJ and CPJ after pancreaticoduodenectomy (DerSimonian-Laird random-effect model). Other definition defined POPF as drainage more than 10,30, and $50 \mathrm{~mL} /$ day of fluid with an amylase level 3 or 5 times greater than normal serum on or after postoperative days 3,5 , and 10 , respectively; ISGPF definition defined POPF as any measurable volume of fluid with an amylase level 3 times greater than normal serum on or after postoperative day 3. Grades A, B, and C are classified according ISGPF definition. ISGPF, International Study Group on Pancreatic Fistula Definition. Weights are from random effects analysis. 
Table 3. Quality assessment of included RCT using Cochrane Risk of Bias Tool

\begin{tabular}{|c|c|c|c|c|c|c|c|}
\hline \multirow[t]{3}{*}{ Study } & \multicolumn{7}{|c|}{ Cochrane Risk of Bias Tool } \\
\hline & \multicolumn{2}{|c|}{ selection bias } & \multicolumn{2}{|c|}{ performance bias } & \multirow{2}{*}{$\begin{array}{l}\text { detection bias } \\
\text { outcome } \\
\text { assessment } \\
\text { blinding }\end{array}$} & \multirow{2}{*}{$\begin{array}{l}\text { attrition bias } \\
\text { incomplete } \\
\text { outcome data }\end{array}$} & \multirow{2}{*}{$\begin{array}{l}\text { reporting bias } \\
\text { selective } \\
\text { reporting }\end{array}$} \\
\hline & $\begin{array}{l}\text { sequence } \\
\text { generation }\end{array}$ & $\begin{array}{l}\text { allocation } \\
\text { concealment }\end{array}$ & $\begin{array}{l}\text { surgeon } \\
\text { blinding }\end{array}$ & $\begin{array}{l}\text { patients } \\
\text { blinding }\end{array}$ & & & \\
\hline Peng & Low risk & Low risk & High risk & Low risk & Low risk & Low risk & Unclear \\
\hline
\end{tabular}

following PD. However, the total hospital costs were higher in the BPJ group.

Since 2002, Peng et al. [19-21] published a series of case reports with $0 \%$ of patients manifesting POPF following BPJ after PD. In 2007, Peng et al. [22] reported a new RCT of 217 patients. The results showed that compared with CPJ, BPJ prevented POPF and also reduced the risk of overall postoperative complications and hospital stay. Therefore, several studies have been conducted to evaluate the safety and efficacy of BPJ to avoid POPF after PD. Two Korean and 1 French studies concluded that the safety of BPJ was comparable to that of CPJ $[32,35,36]$, with a greater efficacy in reducing the rate of POPF and other complications related to pancreatic fistulas $[32,36]$, especially in case of pancreatic remnants with soft texture [36]. However, 3 other Western studies showed the BPJ anastomosis was not associated with lower POPF $[23,33,34]$, and instead increased the $\mathrm{PPH}$ [23].

The mortality rates in our meta-analysis were not significantly different between the BPJ and CPJ groups, which is consistent with previous studies [22, 23, 32-34]. The findings also reinforce the evidence that BPJ was a safe technique [22, 32, 34]. However, the rate of POPF, morbidity, and hospital stay associated with BPJ were not superior to CPJ and the hospital costs were higher in BPJ group, which are inconsistent with the RCT results [22].

The importance of the meta-analysis can be summarized as follows. First, meta-analysis is an important statistical tool combining inconsistent results from independent but similar studies in an effort to improve the estimates of effect size to resolve uncertainty [37]. Second, low-to-moderate heterogeneity was found among all the studies regarding POPF, DGE, reoperation, morbidity, and mortality, which suggested that the heterogeneity might not affect the results. Third, no diversity existed between fixed-effect and random-effect models for all the outcomes. Subgroup analyses based on definition and

Binding Pancreaticojejunostomy
ISGPF POPF grades (A, B, and C) also did not show any significant differences between BPJ and CPJ, which indicate the stability of our results.

However, the present meta-analysis has several limitations. First, the number of patients underwent BPJ ranging from 15 to 106. A possible bias associated with the learning curve of the new technique affected the surgery, contributing to the increased heterogeneity among all the studies targeting $\mathrm{PPH}$, intraoperative blood loss and transfusion, operation time, and hospital stay. Second, only one RCT was included in our meta-analysis and the other 4 studies were OBSs. The criteria in patients undergoing BPJ or CPJ in OBS are based on surgeon's discretion, which resulted in potential selection bias and heterogeneity between RCT and OBS. This limitation is also one reason for the differences between present metaanalysis and Peng's RCT study. Therefore, additional prospective RCTs are needed for future meta-analysis of this topic. Third, increased BMI, soft pancreatic texture, and pancreatic duct diameter no more than $3 \mathrm{~mm}$ are risk factors for POPF [26-28]. Buc et al. [36] concluded that $\mathrm{BPJ}$ improved the rate of POPF, especially in the case of soft pancreas without dilated main pancreatic duct. However, lack of pertinent data in the original studies hindered subgroup analysis based on BMI, pancreatic texture, and pancreatic duct diameter. It is unclear whether BPJ is potentially feasible and effective in these subgroups of patients. Fourth, the definition of POPF and other secondary outcomes is not uniform among the included studies. In 2 studies [23, 33], POPF is defined according to ISGPF criteria as any measurable volume of drain fluid on or after postoperative day 3 , with amylase content greater than 3 times the upper normal serum value [31]. However, other 3 studies defined POPF as the volume of drain fluid $\geq 10 \mathrm{~mL}$ [22], $30 \mathrm{~mL}$ [33] and $50 \mathrm{~mL}$ [35], with amylase level more than $3[22,34]$ or 5 times [32] the upper limit of the normal amylase level after postoperative days 3 [22], 5 [33], and 10 [34], respectively, which poten-

Dig Surg 2017;34:265-280 DOI: $10.1159 / 000453552$ 


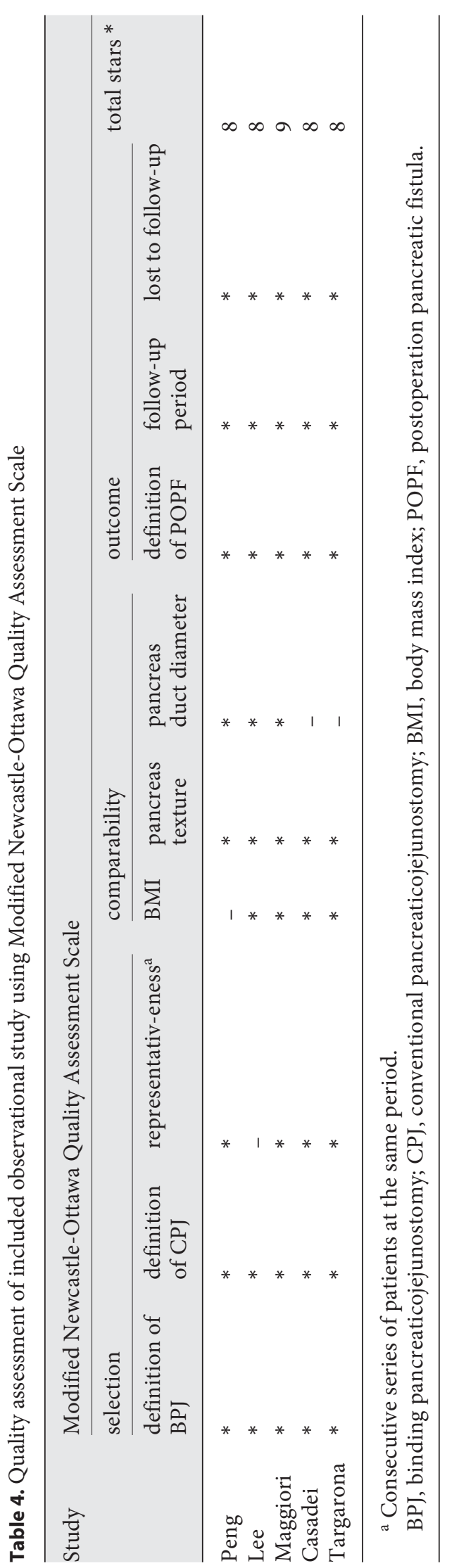

tially excludes a few cases of POPF with low volume output. Although subgroup analysis based on definition indicated no differences between BPJ and CPJ regarding POPF rate, this heterogeneity remains a source of bias regarding the conclusions. The various diagnostic criteria of complications after PD are a major deficiency of current clinical studies and meta-analyses to compare the effect of different surgical techniques and perioperative management in patients who underwent PD. Since 2005, the ISGPF developed novel definition and classification approaches for PF, DEG, and PPH which proved to be useful schemes to decrease the inter-observer variability and these approaches could be used in future studies [31, $38,39]$. Fifth, there was considerable heterogeneity among included studies regarding operation time, intraoperative blood transfusion, and hospital stay and, therefore, might be misleading to quote these pooled results in the present study. Finally, only 5 studies were included in our metaanalysis. The funnel plot cannot be used to test publication bias because of its low statistical power to distinguish chance from real asymmetry [40].

\section{Conclusion}

Our study showed that BPJ is a safe anastomosis method comparable to CPJ. However, no significant differences were found in terms of the incidence of POPF, DGE, $\mathrm{PPH}$, morbidity, mortality, operation time, intraoperative blood loss, blood transfusion, and hospital stay. Instead, BPJ was associated with higher hospital costs. Therefore, the type of digestive tract reconstruction after PD should be selected according to surgical preference.

\section{Acknowledgment}

We thank Lihui Wen (Chonnam National University, Korea) for translating one publication and Simone Kumstel for revising the manuscript.

\section{Disclosure Statement}

The authors declare no conflicts of interest.

\section{Supportive Foundations}

This study was supported by grants from the National Natural Science Foundation of China (No. 81473504) and China Scholarship (No. 201608080195). 


\section{References}

1 Yoshioka R, Yasunaga H, Hasegawa K, Horiguchi H, Fushimi K, Aoki T, Sakamoto Y, Sugawara Y, Kokudo N: Impact of hospital volume on hospital mortality, length of stay and total costs after pancreaticoduodenectomy. Br J Surg 2014;101:523-529.

2 Kimura W, Miyata H, Gotoh M, Hirai I, Kenjo A, Kitagawa $\mathrm{Y}$, Shimada M, Baba $\mathrm{H}$, Tomita N, Nakagoe T: A pancreaticoduodenectomy risk model derived from 8575 cases from a national single-race population (Japanese) using a web-based data entry system: the 30-day and in-hospital mortality rates for pancreaticoduodenectomy. Ann Surg 2014;259:773-780.

3 Winter JM, Cameron JL, Campbell KA, Arnold MA, Chang DC, Coleman J, Hodgin MB, Sauter PK, Hruban RH, Riall TS: 1423 pancreaticoduodenectomies for pancreatic cancer: a single-institution experience. J Gastrointest Surg 2006;10:1199-1210; discussion 12101211.

4 Schmidt CM, Powell ES, Yiannoutsos CT, Howard TJ, Wiebke EA, Wiesenauer CA, Baumgardner JA, Cummings OW, Jacobson LE, Broadie TA: Pancreaticoduodenectomy: a 20 -year experience in 516 patients. Arch Surg 2004;139:718-725; discussion 725-727.

5 Glazer ES, Amini A, Jie T, Gruessner RW, Krouse RS, Ong ES: Recognition of complications after pancreaticoduodenectomy for cancer determines inpatient mortality. JOP 2013;14:626-631.

6 DeOliveira ML, Winter JM, Schafer M, Cunningham SC, Cameron JL, Yeo CJ, Clavien PA: Assessment of complications after pancreatic surgery: a novel grading system applied to 633 patients undergoing pancreaticoduodenectomy. Ann Surg 2006;244:931-937; discussion 937-939.

7 Cecka F, Jon B, Subrt Z, Ferko A: Clinical and economic consequences of pancreatic fistula after elective pancreatic resection. Hepatobiliary Pancreat Dis Int 2013;12:533-539.

8 Ansari D, Tingstedt B, Lindell G, Keussen I, Ansari D, Andersson R: Hemorrhage after major pancreatic resection: incidence, risk factors, management, and outcome. Scand J Surg 2016;pii:1457496916631854.

9 Tingstedt B, Williamsson C, Hansen C, Arifi L, Ansari D, Andersson R: Postoperative pancreatic fistula - impact on outcome, hospital cost and effects of centralization. HPB 2016; 18:e423.

10 Yekebas EF, Wolfram L, Cataldegirmen G, Habermann CR, Bogoevski D, Koenig AM, Kaifi J, Schurr PG, Bubenheim M, NolteErnsting C, Adam G, Izbicki JR: Postpancreatectomy hemorrhage: diagnosis and treatment: an analysis in 1669 consecutive pancreatic resections. Ann Surg 2007;246: 269-280.

11 Menahem B, Guittet L, Mulliri A, Alves A, Lubrano J: Pancreaticogastrostomy is superior to pancreaticojejunostomy for prevention of pancreatic fistula after pancreaticoduodenectomy: an updated meta-analysis of randomized controlled trials. Ann Surg 2015;261: 882-887.

12 Hua J, He Z, Qian D, Meng H, Zhou B, Song $\mathrm{Z}$ : Duct-to-mucosa versus invagination pancreaticojejunostomy following pancreaticoduodenectomy: a systematic review and meta-analysis. J Gastrointest Surg 2015;19:19001909.

13 Gurusamy KS, Koti R, Fusai G, Davidson BR: Somatostatin analogues for pancreatic surgery. Cochrane Database Syst Rev 2013; 4:CD008370.

14 Orci LA, Oldani G, Berney T, Andres A, Mentha G, Morel P, Toso C: Systematic review and meta-analysis of fibrin sealants for patients undergoing pancreatic resection. HPB (Oxford) 2014;16:3-11.

15 Zhou Y, Zhou Q, Li Z, Lin Q, Gong Y, Chen $\mathrm{R}$ : The impact of internal or external transanastomotic pancreatic duct stents following pancreaticojejunostomy. Which one is better? A meta-analysis. J Gastrointest Surg 2012; 16:2322-2335.

16 Bassi C, Butturini G, Molinari E, Mascetta G, Salvia R, Falconi M, Gumbs A, Pederzoli P. Pancreatic fistula rate after pancreatic resection. The importance of definitions. Dig Surg 2004;21:54-59.

17 El Nakeeb A, Salah T, Sultan A, El Hemaly M, Askr W, Ezzat H, Hamdy E, Atef E, El Hanafy E, El-Geidie A, Abdel Wahab M, Abdallah T: Pancreatic anastomotic leakage after pancreaticoduodenectomy. Risk factors, clinical predictors, and management (single center experience). World J Surg 2013;37: 1405-1418.

18 Jang JY, Chang YR, Kim SW, Choi SH, Park SJ, Lee SE, Lim CS, Kang MJ, Lee H, Heo JS: Randomized multicentre trial comparing external and internal pancreatic stenting during pancreaticoduodenectomy. Br J Surg 2016, Epub ahead of print.

19 Peng S, Mou Y, Cai X, Peng C: Binding pancreaticojejunostomy is a new technique to minimize leakage. Am J Surg 2002;183:283285.

20 Peng SY, Mou YP, Liu YB, Su Y, Peng CH, Cai XJ, Wu YL, Zhou LH: Binding pancreaticojejunostomy: 150 consecutive cases without leakage. J Gastrointest Surg 2003;7: 898-900.

21 Peng SY, Wang JW, Li JT, Mou YP, Liu YB, Cai XJ: Binding pancreaticojejunostomy - a safe and reliable anastomosis procedure. HPB (Oxford) 2004;6:154-160.

22 Peng SY, Wang JW, Lau WY, Cai XJ, Mou YP Liu YB, Li JT: Conventional versus binding pancreaticojejunostomy after pancreaticoduodenectomy: a prospective randomized trial. Ann Surg 2007;245:692-698.

23 Maggiori L, Sauvanet A, Nagarajan G, Dokmak S, Aussilhou B, Belghiti J: Binding versus conventional pancreaticojejunostomy after pancreaticoduodenectomy: a case-matched study. J Gastrointest Surg 2010;14:13951400.

24 Moher D, Liberati A, Tetzlaff J, Altman DG: Preferred reporting items for systematic reviews and meta-analyses: the PRISMA statement. Ann Internal medicine 2009;151:264269.

25 Higgins JPT GS: Cochrane Handbook for Systematic Reviews of Interventions version 5.1.0. The Cochrane Collaboration, 2011. wwwcochrane-handbookorg (updated March 2011).

26 Tranchart H, Gaujoux S, Rebours V, Vullierme MP, Dokmak S, Levy P, Couvelard A, Belghiti J, Sauvanet A: Preoperative CT scan helps to predict the occurrence of severe pancreatic fistula after pancreaticoduodenectomy. Ann Surg 2012;256:139-145.

27 Yardimci S, Kara YB, Tuney D, Attaallah W, Ugurlu MU, Dulundu E, Yegen ŞC: A simple method to evaluate whether pancreas texture can be used to predict pancreatic fistula risk after pancreatoduodenectomy. J Gastrointest Surg 2015; 19:1625-1631.

28 Topal B, Fieuws S, Aerts R, Weerts J, Feryn T, Roeyen G, Bertrand C, Hubert C, Janssens M, Closset J: Pancreaticojejunostomy versus pancreaticogastrostomy reconstruction after pancreaticoduodenectomy for pancreatic or periampullary tumours: a multicentre randomised trial. Lancet Oncol 2013;14:655662.

29 Wells G, Shea B, O'connell D, Peterson J, Welch V, Losos M, Tugwell P: The NewcastleOttawa scale (NOS) for assessing the quality of nonrandomised studies in meta-analyses. 2000.http://www.ohri.ca/programs/clinical_ epidemiology/oxford.asp.

30 Shabanzadeh DM, Sørensen LT: Laparoscopic surgery compared with open surgery decreases surgical site infection in obese patients: a systematic review and meta-analysis. Ann Surg 2012;256:934-945.

31 Bassi C, Dervenis C, Butturini G, Fingerhut A, Yeo C, Izbicki J, Neoptolemos J, Sarr M, Traverso W, Buchler M: Postoperative pancreatic fistula: an international study group (ISGPF) definition. Surgery 2005;138:8-13.

32 Lee KJ, Kim SJ, Lee DH: Binding pancreaticojejunostomy compared with dunking pancreaticojejunostomy. Korean J Hepatobiliary Pancreat Surg 2009;13:286-294.

33 Casadei R, Ricci C, Silvestri S, Campra D, Ercolani G, D’Ambra M, Pinna AD, Fronda GR, Minni F: Peng's binding pancreaticojejunostomy after pancreaticoduodenectomy. An Italian, prospective, dual-institution study. Pancreatology 2013;13:305-309.

34 Targarona J, Barreda L, Pando E, Barreda C: [Is Peng's pancreaticojejunal anastomosis more effective than mucosa-mucosa anastomosis in duodenopancreatectomy for pancreatic and peri-ampullary tumours?]. Cir Esp 2013;91:163-168. 
35 Kim JM, Hong JB, Shin WY, Choe YM, Lee GY, Ahn SI: Preliminary results of binding pancreaticojejunostomy. Korean J Hepatobiliary Pancreat Surg 2014;18:21-25.

36 Buc E, Flamein R, Golffier C, Dubois A, Nagarajan G, Futier E, Pezet D: Peng's binding pancreaticojejunostomy after pancreaticoduodenectomy: a French prospective study. J Gastrointest Surg 2010;14:705-710.

37 Imperiale TF: Meta-analysis: when and how. Hepatology 1999;29(6 suppl):26S-31S.
38 Wente MN, Bassi C, Dervenis C, Fingerhut A, Gouma DJ, Izbicki JR, Neoptolemos JP, Padbury RT, Sarr MG, Traverso LW, Yeo CJ, Büchler MW: Delayed gastric emptying (DGE) after pancreatic surgery: a suggested definition by the international study group of pancreatic surgery (ISGPS). Surgery 2007;142:761-768.

39 Wente MN, Veit JA, Bassi C, Dervenis C, Fingerhut A, Gouma DJ, Izbicki JR, Neoptolemos JP, Padbury RT, Sarr MG, Yeo CJ, Büchler MW: Postpancreatectomy hemor- rhage (PPH): an international study group of pancreatic surgery (ISGPS) definition. Surgery $2007 ; 142: 20-25$.

40 Sterne JA, Sutton AJ, Ioannidis JP, Terrin N Jones DR, Lau J, Carpenter J, Rücker G, Harbord RM, Schmid CH, Tetzlaff J, Deeks JJ, Peters J, Macaskill P, Schwarzer G, Duval S, Altman DG, Moher D, Higgins JP: Recommendations for examining and interpreting funnel plot asymmetry in meta-analyses of randomised controlled trials. BMJ2011;343:d4002. 